\title{
Study of Metal/Polymer Interface of Parts Produced by a Hybrid Additive Manufacturing Approach
}

\author{
M.R. Silva ${ }^{1, a^{*}}$, J. Domingues ${ }^{1, b}$, J. Costa $^{1, c}$, A. Mateus ${ }^{1, d}$ and C. Malça ${ }^{2, e}$ \\ ${ }^{1}$ Centro para o Desenvolvimento Rápido e Sustentado do Produto, Instituto Politécnico de Leiria, \\ Portugal \\ ${ }^{2}$ Departamento de Engenharia Mecânica, Instituto Superior de Engenharia de Coimbra, Portugal \\ amiguel.r.silva@pleiria.pt, bjorge.domingues@ipleiria.pt, cjoao.p.costa@pleiria.pt, \\ dartur.mateus@ipleiria.pt, ${ }^{e}$ candida@isec.pt
}

Keywords: Selective Laser Melting (SLM); Stereolithography (SL); Hybrid Additive Manufacturing process; Metal/polymer parts; Metal/polymer interface components.

\begin{abstract}
The additive manufacturing of multimaterial parts, e.g. metal/plastic, with functional gradients represents for current market demands a great potential of applications [1]. Metal Polymer parts combine the good mechanical properties of the metals with the low weight characteristics, good impact strength, good vibration and sound absorption of the polymers. Nevertheless, the coupling between metal and polymers is a great challenge since the processing factors for each one of them are very different. In addition, a system that makes the hybrid processing - metal/polymer - using only one operation is unknown [2,3]. To overcome this drawback, a hybrid additive manufacturing system based on the additive technologies of SLM and SL was recently developed by the authors. The SLM and SL techniques joined enabling the production of a photopolymerization of the polymer in the voids of a 3D metal mesh previously produced by SLM [4]. The purpose of this work is the study on the metal/polymer interface of hybrid parts manufactured from the hybrid additive manufacturing system [5]. For this, a core of tool steel (H13) and two different types of photopolymers: one elastomeric (BR3D-DL-Flex) and another one rigid (BR3D-DL-Hard) are considered. A set of six samples for each one of metal core/polymer combination was manufactured and submitted to tensile tests.
\end{abstract}

\section{Introduction}

Direct Digital manufacturing equipment for processing hybrid parts give an amazing world of possibilities to produce parts made of different material combinations such as metal/polymer [6]. The result are hybrid components that combine the best properties from both materials. Nevertheless, the metal/polymer interface quality determines the global performance of the parts. The interface strength is also influenced by the surface roughness of the bonded materials [7]. Another material property that could influence the interface between metal/polymer is the wettability [8]. The measurement of contact angle reflects the wettability of a material. The contact angle value depends mainly on the relationship between the affinity forces between the liquid and the material in question. When these forces are high, the contact angle is less than 90 degrees, and results in the ability of the liquid to wet the surface of the material [9]. In addition, the mechanical strength of different material combination was evaluated through tensile tests.

\section{Materials and Methods}

H13 tool steel metal sample production. The metal sample parts were produced by additive manufacturing technique, powder bed fusion, in $\mathrm{H} 13$ tool steel powder from SLM Solutions, with a layer thickness of $30 \mu \mathrm{m}$ and energy density of $80 \mathrm{~J} / \mathrm{mm}^{3}$. The sample produced are shown in Fig. 1. Although the select processing SLM parameters were standard one, the part geometry and build orientation influence the part surface roughness $[10,11]$. 

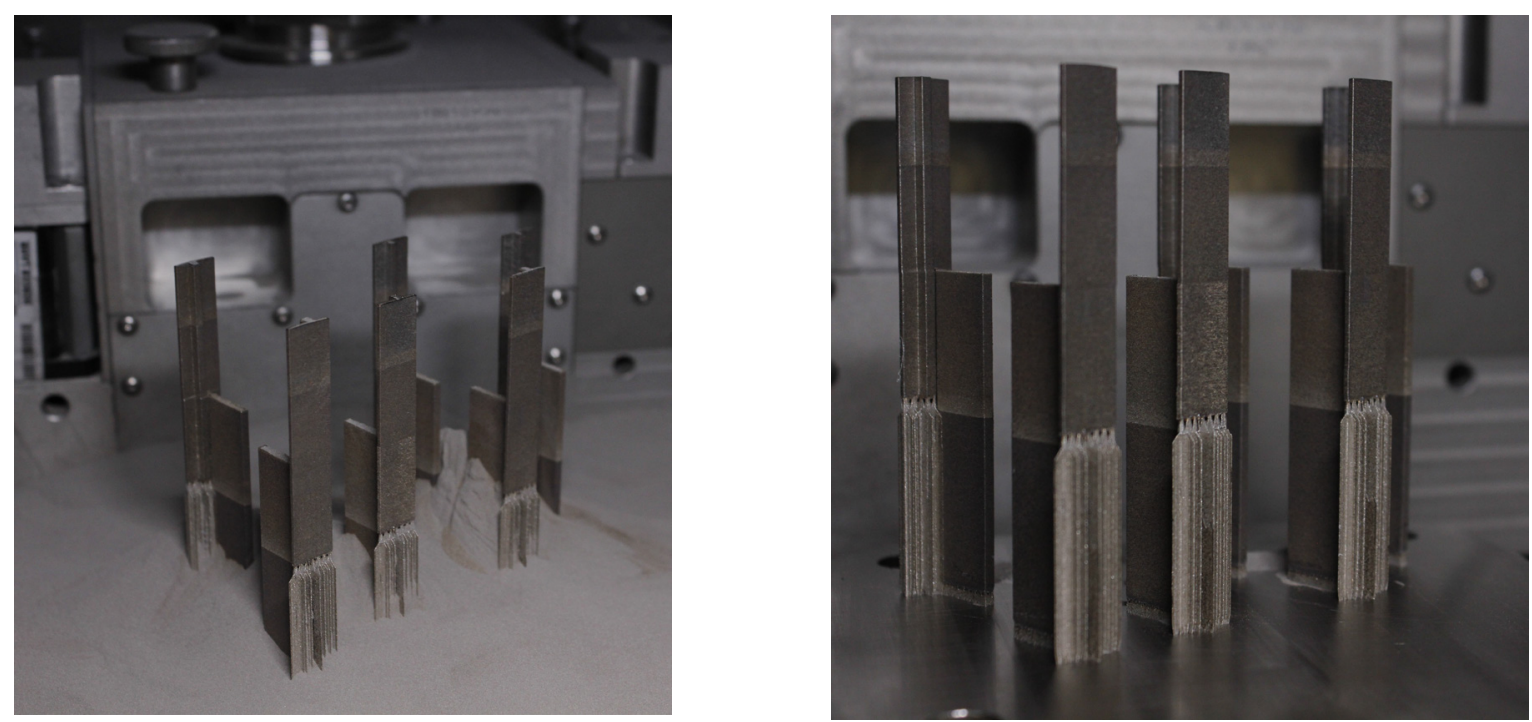

Figure 1 - SLM build platform with metal samples.

Each sample was then subject to a set of tests whose goal was to evaluate the materials wettability (metal and polymers wetting properties), through the contact angle measurements to evaluate the surface roughness.

Polymeric sample production. The polymeric samples parts were produced by the stereolithography additive manufacturing prototype equipment developed by the authors. This new equipment presents an innovative approach to produced hybrid parts by using a LCD projector as electromagnetic energy source, which is not perpendicular to the resin free surface. The LCD projector is placed in specific angle to avoid core shadows as illustrated in Fig 2.

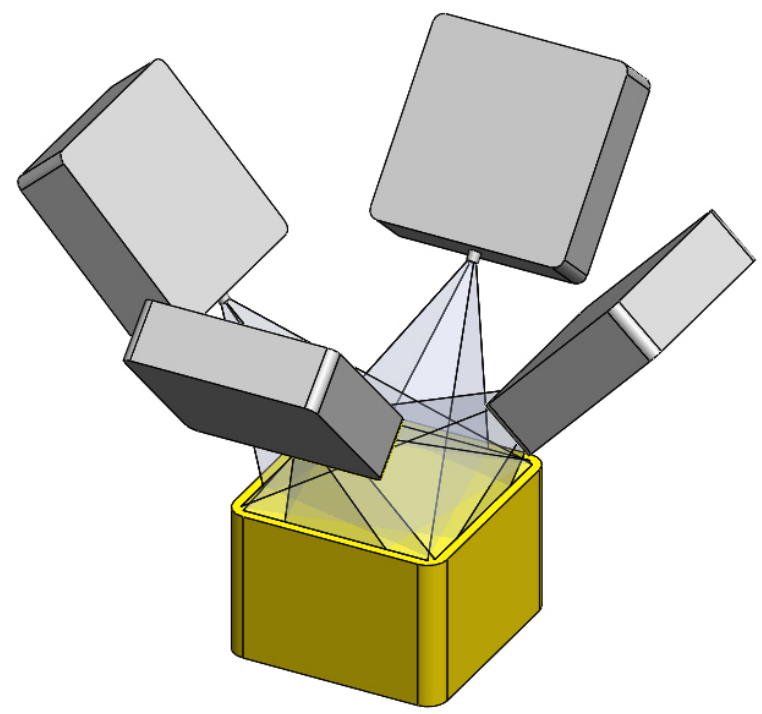

Figure 2 - Next.parts concept.

This prototype equipment is controlled by an Arduino mega board running an experimental algorithm. Regarding the hardware a homemade XYZ gantry and DLP projector, ASUS S1 mobile led with 200 lumens intensity and $854 \times 480$ pixel resolution were used as depicted in Fig 3. 


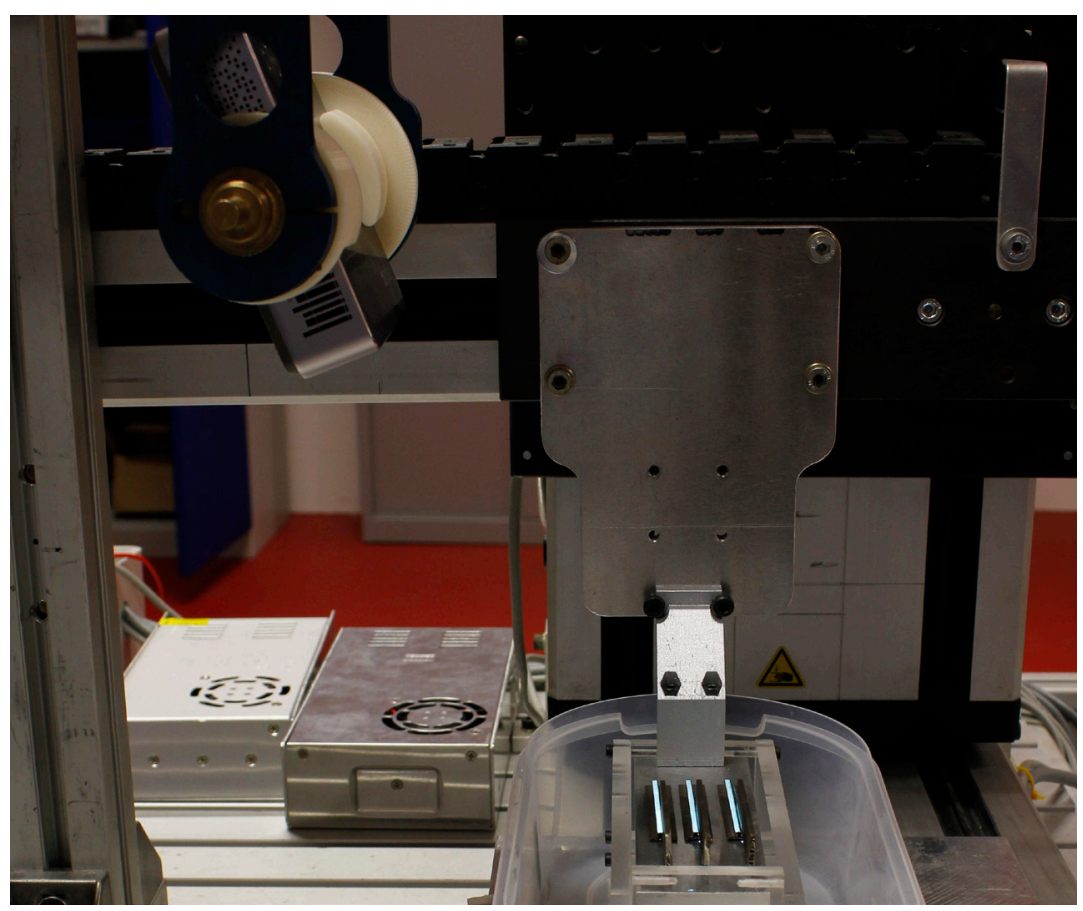

Figure 3 - Prototype Next.parts polymerizing.

In this study two different thermoset resins from PhotoCentric 3D: the BR3D-DL-Flex and the BR3DDL-Hard - were used, and whose specifications are summarized in Table 1.

Table 1 - PhotoCentric 3D resin specifications [12].

BR3D-DL-Flex

BR3D-DL-Hard

\begin{tabular}{|c|c|c|}
\hline Viscosity [cPs] (@25 ${ }^{\circ} \mathrm{C}$ Brookfield spindle 3) & 200 & 230 \\
\hline Hardness [Shore] (After post exposure) & $85 \mathrm{~A}$ & $77 \mathrm{D}$ \\
\hline $\begin{array}{l}\text { Tensile strength [MPa] ASTM D638 (After post } \\
\text { exposure) }\end{array}$ & 4.9 & 35 \\
\hline $\begin{array}{l}\text { Tensile strength [MPa] ASTM D638 (Before post } \\
\text { exposure) }\end{array}$ & 1.5 & 15 \\
\hline $\begin{array}{l}\text { Tensile modulus [MPa] ASTM D638 (After post } \\
\text { exposure) }\end{array}$ & -- & 2060 \\
\hline Elongation at break [\%] ASTM D638 & 60 & 4 \\
\hline Heat deflection temp $\left[{ }^{\circ} \mathrm{C}\right]$ & -- & 60 \\
\hline Storage $\left[{ }^{\circ} \mathrm{C}\right]$ & $10<t>50$ & $10<t>50$ \\
\hline Density [g/cm3] & 1.18 & 1.19 \\
\hline
\end{tabular}


Table 2 shows the settings of LCD parameters for the stereolithographic processing.

Table 2 - Polymeric processing parameters.

\begin{tabular}{|l|c|c|}
\hline & BR3D-DL-Flex & BR3D-DL-Hard \\
\hline Projection exposure angle $\left[^{\circ}\right.$ ] & 15 & 15 \\
\hline Projection distance $[\mathbf{m m}]$ & 250 & 250 \\
\hline Exposure time [s] & 4 & 12 \\
\hline Wait time [s] (between layer exposure) & 8 & 200 \\
\hline Layer height $[\boldsymbol{\mu m}]$ & 100 & 18 \\
\hline Room temperature $\left[{ }^{\circ} \mathbf{C}\right]$ & 18 & 2 \\
\hline Post processing $[\mathbf{h}](\mathbf{u v}$ chamber exposure) & 2 & \\
\hline
\end{tabular}

This study used a two steps hybrid approach to produced specimen's samples. First the metal part was produced by SLM; and in the second step a resin was polymerized around the metal core using the stereolithography developed prototype as show in Fig. 4. Three sample specimens were produced simultaneous.

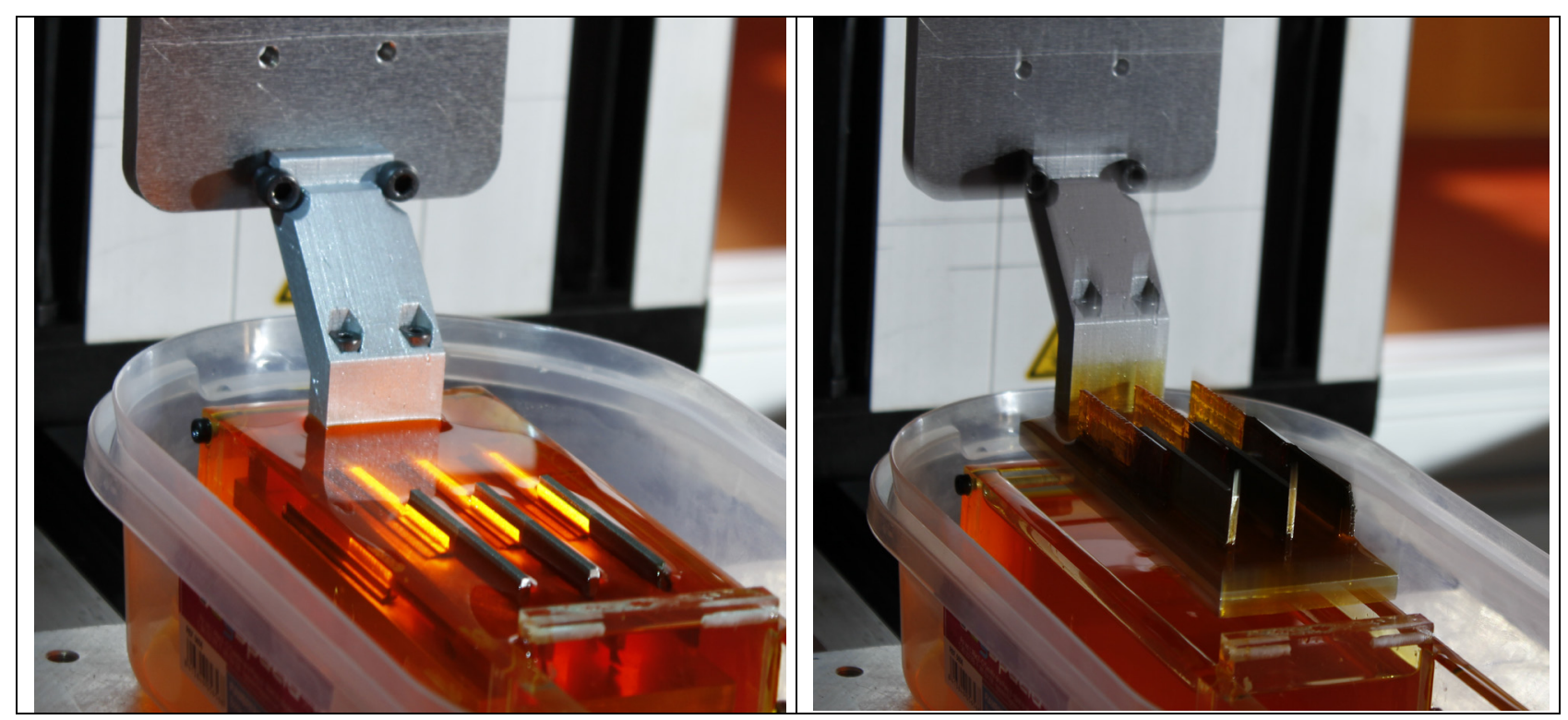

Figure 4 - Resin polimerization step.

Tensile tests of specimens. The testing samples, shown in Fig. 5, were build based on ASTM D3163 standard test method for determining strength of adhesively bonded rigid plastic lap-shear joints in shear by tension loading, the proof sample dimensions were adapted to the available build platform dimensions of the polymerization prototype device developed. 


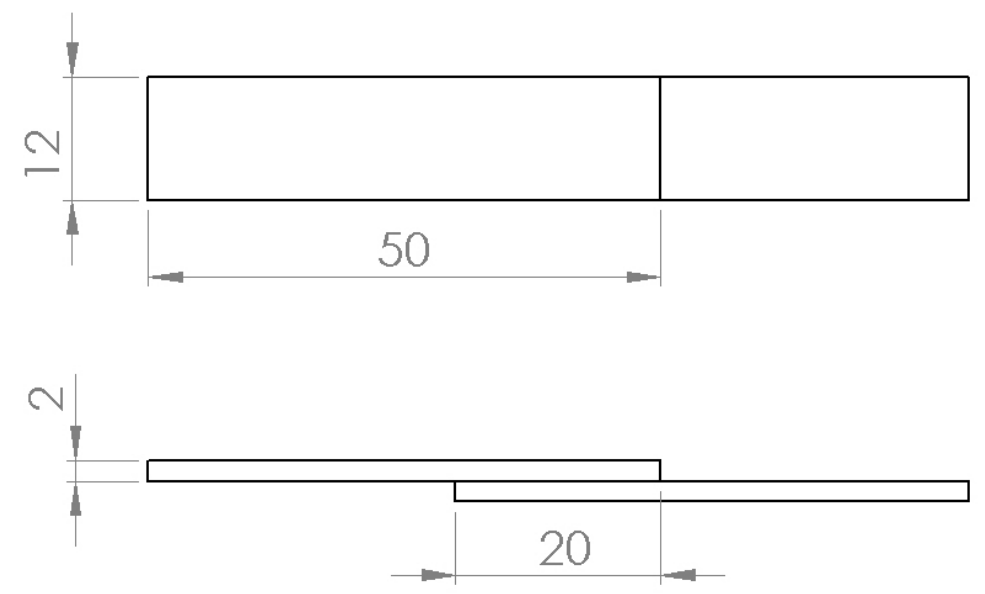

Figure 5 - Test sample dimensions.

Tensile test specimens were printed with a support structure (gabarit) attached to promote the required position, i.e. verticality in the build platform of the polymerization vat as represented in Fig. 6 . After the resin layers was finished, the support structure is removed to perform mechanical tests.

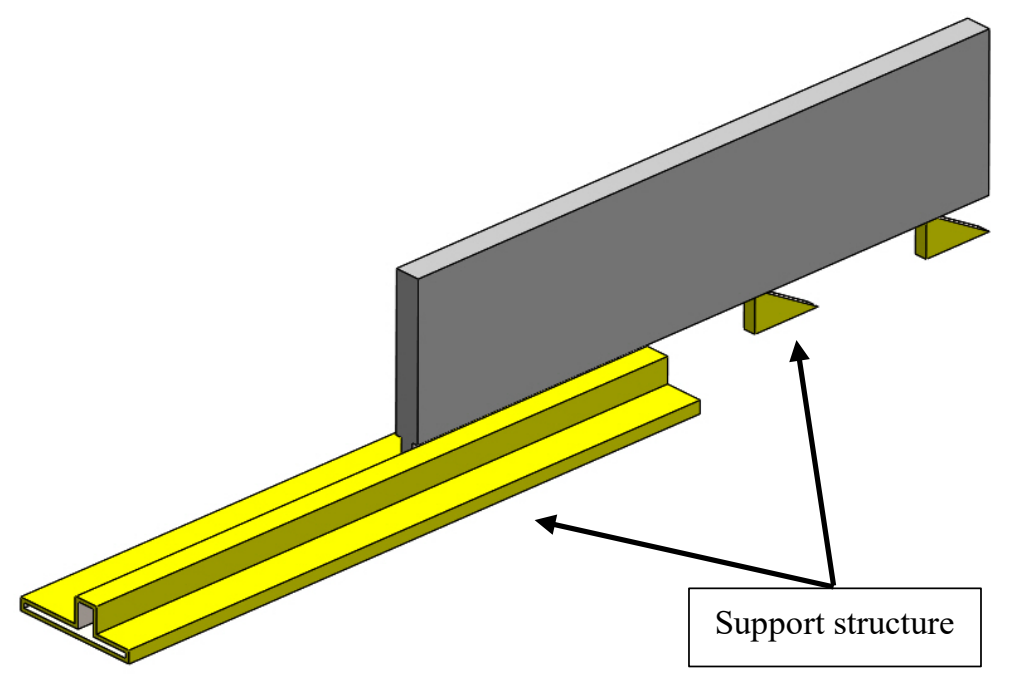

Figure 6 - Sample test with a support structure.

\section{Results and Discussion}

Measurement of surface roughness. The surface roughness was measured to evaluate the influence in the metal/polymer adhesion of the different material combination samples manufactured. The mechanical profilometer Bruser DeckTac XP with the roundness of the tip of $2 \mu \mathrm{m}$ was used. On each of the 6 samples, the roughness was measured in three areas according the longitudinal orientation.

As expected the mean surface roughness measurement results show that a mean $R_{\mathrm{z}}$ was $32.3+-3.3$ $\mu \mathrm{m}$ was reached for the specimen with the best resulting surface roughness; while for the specimen with worst resulting surface a mean value of $35.87+-4.1 \mu \mathrm{m}$ for the roughness was measured.

Measurement of contact angle. The experimental apparatus of these tests was supported by an Optical Tensiometer Attension model Theta with the accuracy of $0.1 \%$, which basically consists of an adjustable base (with three degrees of freedom), a light source, a drop generation system and an image acquisition system which includes a monochromatic charge-coupled device (CCD) coupled to a microscope. The drops are generated at the end of a needle that is fixed to an adjustable support (with two degrees of freedom) which allows the distance and position of the needle (and consequently 
of the drop) to be adjusted in relation to the surface under study. The flow of liquid feeding the needle is pumped by a small syringe. The entire system is controlled by the One Attension software to ensure the formation of uniform drops. The test liquid used here was water. All assays were performed in triplicate. From the analysis of the contact angle results, displayed in Fig. 7, it will be seen that both materials are hydrophilic. The contact angle established between a drop of water and the various materials in question is less than $90^{\circ}$. However, the resin has a much higher degree of hydrophilicity when compared to those verified for steel. The contact angle of a water drop to the resin is much lower approaching zero, compared to the steel approaching the hydrophobicity threshold, when approaching to $90^{\circ}$. Thus, a moderate affinity between both materials is expected, which, although having a hydrophilic character, are found in considerably different hydrophilicity ranges.

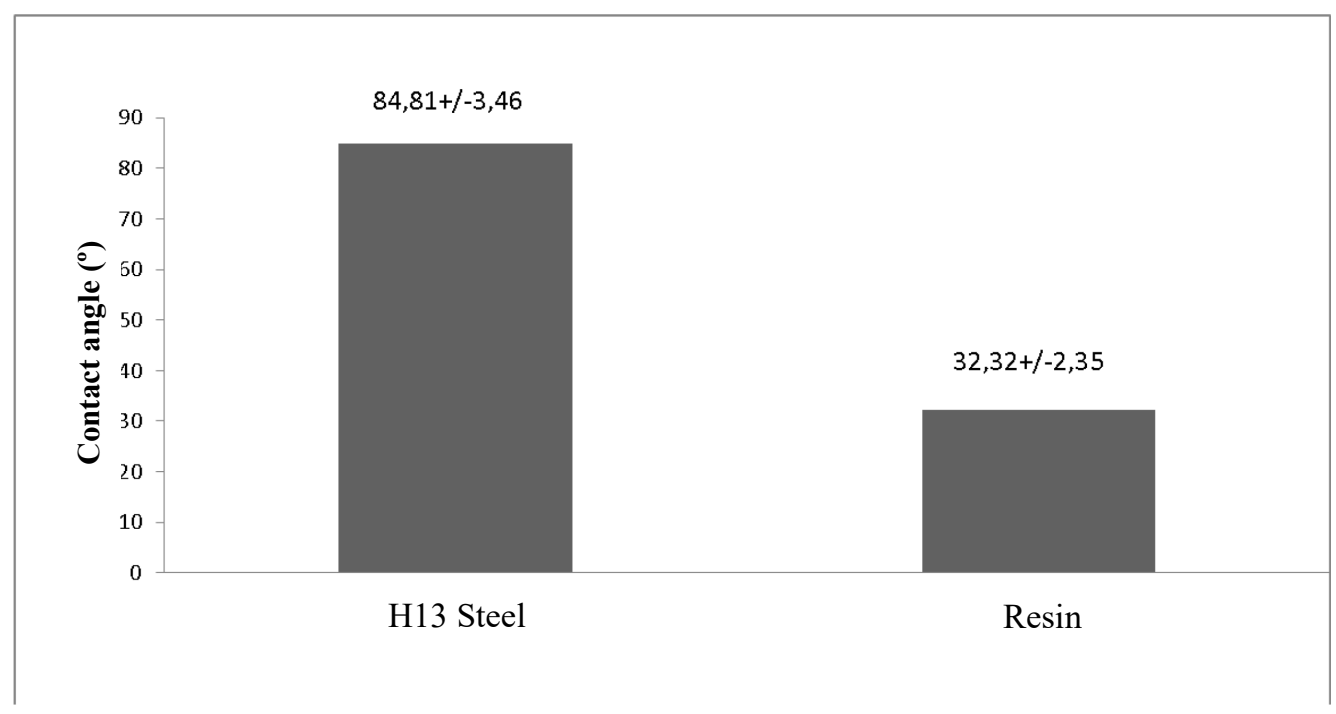

Figure 7 - Contact angle results.

Mechanical tests. With the purpose of obtaining the hybrid component mechanical characterization and the adhesion between metal and polymer, uniaxial tensile tests were performed in a set of samples specimens for each resin type. After hybrid building process was finished, the samples were cleaned and manually polished with a 220-grit sandpaper to eliminate burrs and edges and to standardize their dimensions. The uniaxial tensile tests were performed using a Zwick electrochemical test equipment, model Z100 applying a force range of $100 \mathrm{kN}$. At the end of prestressing part, the mechanical extensometer with an initial length of $l_{0}=40 \mathrm{~mm}$ between the pins was attached to the sample. Concerning setup tests, were done under position control with a loading rate of $1.27 \mathrm{~mm} / \mathrm{min}$. The specimens were taken to the breaking point (Fig. 8) and the data obtained analyzed and processed. Considering an interface area (cross section) of $24 \mathrm{~mm}^{2}$, the shear failing stress was calculated by dividing the applied force for the interface area. 


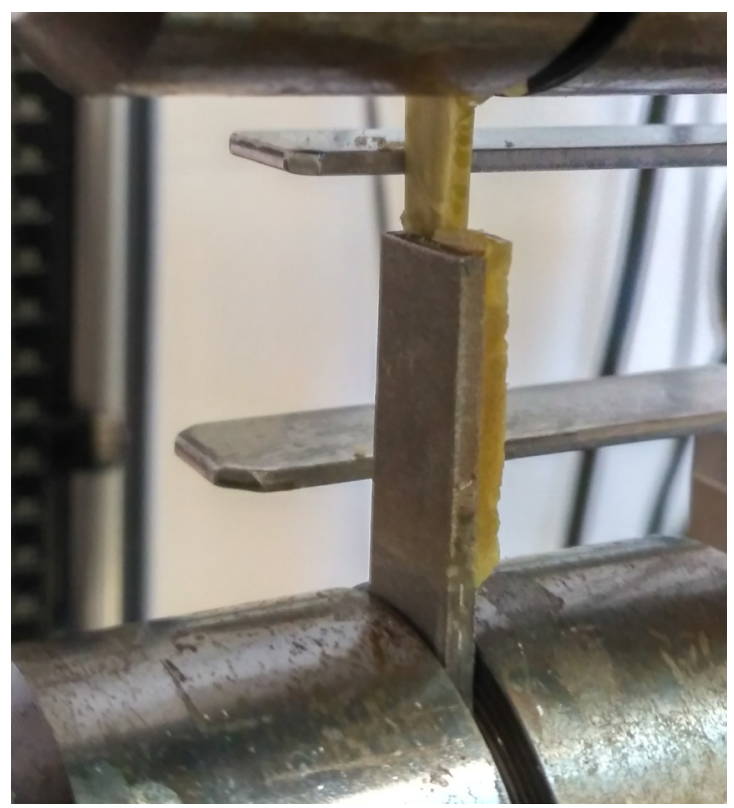

Figure 8 - Sample test.

Regarding mechanical tests, a value of $25 \mathrm{MPa}$ for the average tensile stress is reached for the BR3DDL-hard as displayed in, Fig.9 a). As shown in Fig. 10, for all the samples, the break of the resin sample occurs outside the interface region, occurring near it (stock break failure). For the BR3D-DLFlex an elastomer behavior was observed as depicted in Fig. 10 b).
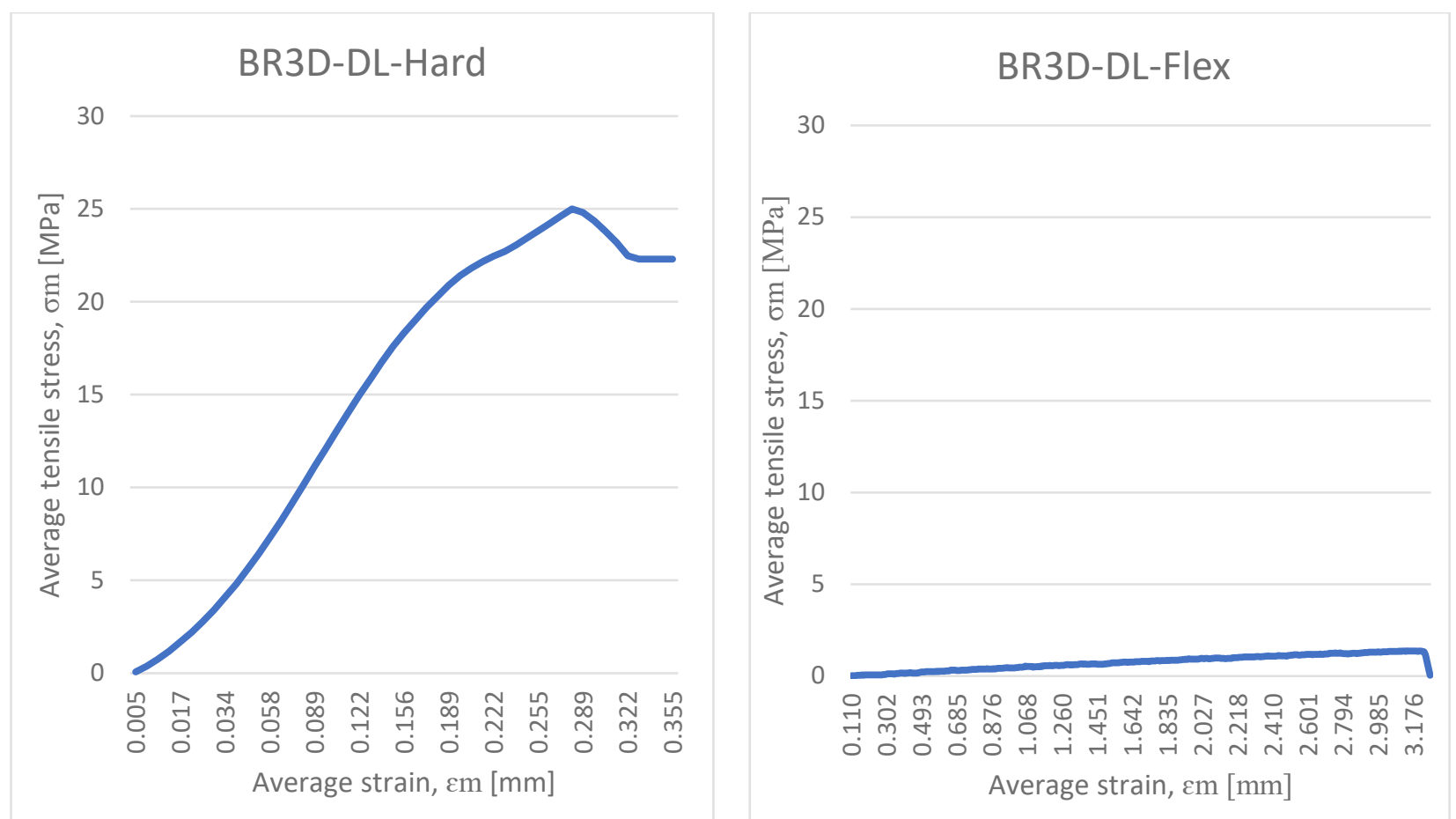

Figure 9 - Average tensile stress/strain results for sample tests a) BR3D-DL-Hard and b) BR3DDLFlex. 


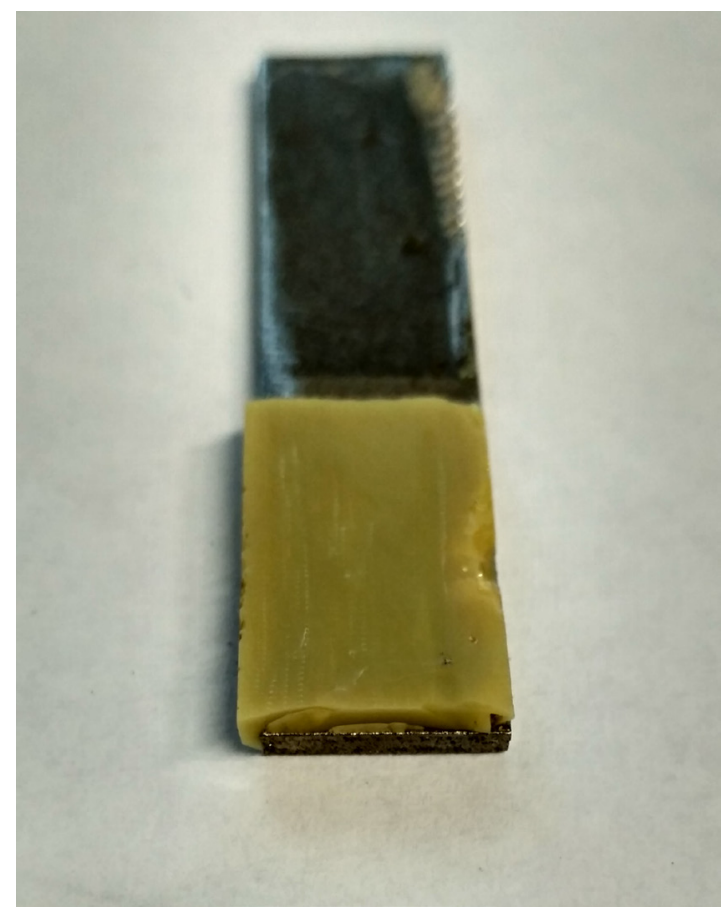

Figure 10 - Sample mode failure.

\section{Conclusions and Future Works}

The Mechanical testing study couldn't determinate interface metal/polymer failure shear stress. The hybrid sample interface shows a bigger strength than resin's.

The polymerized resin exhibit poor surface quality, when compared with single plastic part without metallic core.

Regarding future works, we could list the following number of main items:

Testing samples with smaller interface area in order to quantify the interface shear strength.

Testing different surfaces finishing (roughness) to establish the influence in core-plastic adhesion.

Test different processing parameters (stereolithography). Study the influence of the metallic core in plastic surface quality and if it can be established a relation between metal light reflection and resin polymerization.

\section{Acknowledgments}

This research work was supported by the Portuguese Foundation for Science and Technology (FCT) and Centro2020 through the Project reference: UID/Multi/04044/2013, PAMI ROTEIRO/0328/2013 ( $\mathrm{N}^{\circ}$ 022158) and Portuguese National Innovation Agency (ANI) through the Project reference POCI-01-0247-FEDER-017963, NEXT.parts - Next Generation of Advanced Hybrid Parts (co-promotion $\left.n^{\circ} 17963\right)$.

\section{References}

[1] S.Antoniw, N. McCarthy, E. Pacey, B. Parkin, P. Shelton. Additive Manufacturing: Opportunities and Constraints, Royal Academy of Engineering, 1st edition, London, 2013.

[2] W. Gao, Y. Zhang, D. Ramanujan et al. The status, challenges, and future of additive manufacturing in engineering. Computer-Aided Design, 2015, pp. 69, 65-89.

[3] C. Zbigniew. Direct Digital Manufacturing, New Product Development and Production Technology. Economics and Organization of Enterprise, 2008, pp. 29-37. 
[4] I. Yadroitsev, P. Shishkovsky, I. Bertrand, I. Smurov. Manufacturing of fine-structured 3D porous filter elements by selective laser melting. Applied Surface Science, 2009, pp. 255, 5523-5527.

[5] T. Rechtenwald, T. Frick, M. Schmidt. Manufacturing of highly integrated mechatronic modules by using the technology of embedding stereolithography. Physics Procedia, 2010, pp. 5, 573-586.

[6] B. Niese, T. Stichel, P. Amend, U. Urmoneit, S. Roth, M. Schmidt, Manufacturing of Conductive Circuits for Embedding Stereolithography by Means of Conductive Adhesive and Laser Sintering. Physics Procedia, 2014, pp. 56, 336-344.

[7] A.M. Pereira, J.M. Ferreira, F.V. Antunes, P.J. Bártolo. Analysis of manufacturing parameters on the shear strength adhesive single-lap joints, Journal of Materials Processing Technology, 2009.

[8] D.Y. Kwok, A.W. Neumann, Contact angle measurement and contact angle interpretation, In Advances in Colloid and Interface Science, Volume 81, Issue 3, 1999, Pages 167-249.

[9] Hanyang Gu, Chi Wang, Shengjie Gong, Yong Mei, Huang Li, Weimin Ma, Investigation on contact angle measurement methods and wettability transition of porous surfaces, In Surface and Coatings Technology, Volume 292, 2016, Pages 72-77.

[10] B.-D. Joo, J.-H. Jang, J.-H. Lee et al. Selective laser melting of Fe-Ni-Cr layer on AISI H13 tool steel. Transactions of Nonferrous Metals Society of China, 2009, 19, pp. 921-924.

[11] S. Dadbakhsh, L. Hao, P.G.E. Jerrard, D.Z. Zhang. Experimental investigation on selective laser melting behaviour and processing windows of in situ reacted $\mathrm{Al} / \mathrm{Fe} 2 \mathrm{O} 3$ powder mixture. Powder Technology, 2012, pp. 112-121, 231.

[12] Information on http://photocentric3d.com (accessed 19th September 2017). 